\title{
Predicting Psychological and Subjective Well-Being from Personality: Incremental Prediction from 30 Facets over the Big 5
}

\author{
Jeromy Anglim, Sharon Grant ${ }^{1}$
}

Citation Information: Anglim, J., \& Grant, S. (2016). Predicting Psychological and Subjective Well-Being from Personality: Incremental Prediction from 30 Facets over the Big 5. Journal of Happiness Studies, 17, 59-80. https://dx.doi.org/10.1007/s10902-014$\underline{9583-7}$

\begin{abstract}
This study investigated the relationship between the Big 5, measured at factor and facet levels, and dimensions of both psychological and subjective well-being. Three hundred and thirty-seven participants completed the 30 Facet International Personality Item Pool Scale, Satisfaction with Life Scale, Positive and Negative Affectivity Schedule, and Ryff's Scales of Psychological Well-Being. Cross-correlation decomposition presented a parsimonious picture of how well-being is related to personality factors. Incremental facet prediction was examined using double-adjusted $\mathrm{r} 2$ confidence intervals and semi-partial correlations. Incremental prediction by facets over factors ranged from almost nothing to a third more variance explained, suggesting a more modest incremental prediction than presented in the literature previously. Examination of semi-partial correlations controlling for factors revealed a small number of important facet-well-being correlations. All data and $\mathrm{R}$ analysis scripts are made available in an online repository.
\end{abstract}

Keywords: Subjective well-being, psychological well-being, personality, Big 5. personality facets

\section{Introduction}

Understanding the relationship between personality and well-being is of fundamental importance for both theoretical and applied reasons. For one, the relationship of personality to well-being may shed light on the temporal stability of well-being. It can also be helpful to understand the role of personality when designing interventions targeted at increasing well-being. However, at present, it is unclear whether facet-level or factorlevel personality analysis is superior for understanding well-being. Researchers need an unbiased assessment of this issue, given the reduction in parsimony that results when moving away from broad models of personality such as the Five Factor Model. In addition,

\footnotetext{
${ }^{1}$ This article may not exactly replicate the authoritative document published in the journal. It is not the copy of record. The above doi links to the copy of record. Supplementary data and code is also available from the above doi. Jeromy Anglim, School of Psychology, Deakin University; Sharon Grant, Faculty of Life and Social Sciences, Swinburne University of Technology. We thank Sue Carmen for her assistance with data collection. Correspondence concerning this article should be addressed to Jeromy Anglim, School of Psychology, Deakin University, 221 Burwood Highway, Burwood, 3125 Victoria, Australia. Email: jeromy.anglim@deakin.edu.au
} 
little is currently known about the relationship between psychological well-being and personality facets. In what follows, we describe subjective well-being (SWB), psychological well-being (PWB) and the Five Factor Model (FFM), and review previous work on personality and well-being before outlining the objectives for the current study, which illustrates a new approach for assessing the incremental variance of personality facets over factors.

\subsection{Subjective and Psychological Well-Being}

The literature on SWB is expansive (Diener \& Choi, 2009; Diener, Oishi, \& Lucas, 2003; Diener, Suh, Lucas, \& Smith, 1999; Lucas \& Diener, 2008). SWB has been defined and measured in a variety of ways and can include happiness and quality of life measures, but a common approach is to operationalize SWB as a composite of satisfaction with life, high positive affect, and low negative affect (Deci \& Ryan, 2008; Diener, 1984; Lucas, Diener, \& Suh, 1996). This operationalization is adopted in the current study.

The construct of PWB was developed in response to a perceived failure of SWB to capture various humanistic concepts of well-being related to identity, meaning, and relatedness (McGregor \& Little, 1998; Ryan \& Deci, 2001; Ryff \& Keyes, 1995). Ryff (1989) proposed a six dimensional model of PWB composed of autonomy, environmental mastery, personal growth, positive relations, purpose in life, and self-acceptance. The same author also developed a measure of these six dimensions that has subsequently been used in several studies (for a review see, Keyes, Shmotkin, \& Ryff, 2002). Studies have shown that environmental mastery and self-acceptance overlap substantially with SWB (Compton, 1998; Keyes et al., 2002; McGregor \& Little, 1998; Ryff \& Keyes, 1995) but that the other dimensions are more distinct, correlating only moderately with SWB measures (Compton, 1998; Keyes et al., 2002; McGregor \& Little, 1998; Ryff \& Keyes, 1995).

While situational factors lead to short-term fluctuation and in some cases long-term change in well-being, substantial research has supported a dispositional perspective of wellbeing. Building on ideas such as the "hedonic treadmill" (Brickman \& Campbell, 1971), Headey and Wearing (1992) proposed that while life events can temporarily alter wellbeing, well-being has a set point which varies between individuals. Genetic and twin studies have established a hereditary basis for the stable component of well-being (Bouchard Jr \& Loehlin, 2001; Lykken \& Tellegen, 1996; Weiss, Bates, \& Luciano, 2008). Furthermore, a 17 year longitudinal study (Fujita \& Diener, 2005) found that satisfaction with life showed substantial stability over time, albeit at about half the level of personality traits. Thus, personality traits provide an important means of understanding the stability in well-being.

\subsection{Personality}

Historically, trait research began with a proliferation of traits which was later followed by various attempts at data reduction and eventually a movement to the Big 5 (Costa \& McCrae, 1992; Goldberg, 1993; McCrae \& John, 1992), typically labeled neuroticism, extraversion, openness, conscientiousness, and agreeableness. More recently, researchers responding to the success of the Big 5 have called for even higher level factor models (Digman, 1997; Musek, 2007) and more detailed lower level models (Paunonen \& Ashton, 2001; Paunonen \& Jackson, 2000). Several test publishers have developed facetlevel models of the Big 5, which aim to capture both the Big 5 and their constituent lowerlevel facets (Costa \& McCrae, 1992; Goldberg, 1992; John \& Srivastava, 1999). Despite 
some discontent over the dominance of the Big 5, the taxonomy provides an organizing framework for understanding different traits.

\subsection{Personality Factors and Well-Being.}

The relationship between personality and SWB has received substantial research attention, with neuroticism and extraversion emerging as important correlates. DeNeve and Cooper (1998) conducted a large meta-analysis of correlations between SWB and personality traits. As most of the included studies were conducted prior to the emergence of the Big 5 as a unifying framework, they categorized the studies according to the Big 5 . More recently, Steel, Schmidt, and Shultz (2008) conducted an updated meta-analysis presenting separate results using common measures of the Big 5. Both meta-analyses found that neuroticism had the highest correlation with life satisfaction and negative affectivity while extraversion had the highest correlation with positive affect.

Only a few studies have examined correlations between personality and PWB (Bardi \& Ryff, 2007; Butkovic, Brkovic, \& Bratko, 2012; Grant, Langan-Fox, \& Anglim, 2009; Keyes et al., 2002; Schmutte \& Ryff, 1997). Such studies suggest that neuroticism, extraversion and conscientiousness are the major correlates for most PWB dimensions. More generally, dimensions of PWB tend to be better predicted by personality than are SWB dimensions, and PWB tends to correlate with more of the Big 5 dimensions.

In order to compare Big 5 correlates of SWB versus PWB, Grant et al. (2009) used a model constraints approach. After reversing neuroticism and negative affect, they found support for a model where personality traits varied in their average correlation with wellbeing, and well-being dimensions varied in their average correlation with personality. Average well-being correlations were largest for neuroticism $(r=-.44)$, followed by extraversion $(r=.31)$, conscientiousness $(r=.29)$, openness $(r=.12)$, and agreeableness $(r=.11)$. PWB variables tended to correlate more with personality than did SWB variables. There were also several unique combinations of personality factors and well-being variables that had larger correlations than would be expected from their component averages. These were neuroticism with negative affect, extraversion with positive affect and positive relations, conscientiousness with personal growth and purpose in life, agreeableness with positive relations, and openness with personal growth. In the opposite direction, autonomy correlated less with agreeableness than would be expected by component averages.

\subsection{Personality Facets and Well-Being}

While the Big 5 provides a useful organizing framework for personality research, several researchers have raised concerns that a more detailed model of personality is required to adequately predict criteria of interest such as well-being (Paunonen \& Ashton, 2001; Paunonen \& Jackson, 2000). To provide a richer model of personality, many personality tests include both high-level factors, such as the Big 5, and nested lower-level facets. For example, the NEO-PI-R (Costa \& McCrae, 1992) includes six facets for each factor of the Big 5. So for example, the neuroticism factor is composed of the facets of anxiety, hostility, depression, self-consciousness, impulsiveness, and vulnerability to stress. As a result, many studies have examined facet-level correlations with a range of outcome variables (e.g., Paunonen \& Ashton, 2001), and a few have examined facet-level correlations with well-being (e.g., Quevedo \& Abella, 2011; Schimmack, Oishi, Furr, \& Funder, 2004). 
Initial research on facet-level prediction of SWB suggested that facets enable a dramatic increase in prediction of SWB (Quevedo \& Abella, 2011; Schimmack et al., 2004; Steel et al., 2008), yet critical analysis suggests that incremental prediction may be more modest. For example, Quevedo and Abella (2011) examined prediction of SWB by NEO Big 5 and 30 facets as well as additional scales of optimism, self-esteem, and perceived social support. Using stepwise regression predicting life satisfaction they found that adjusted r-squared was .16 with the NEO Big 5 as predictors, .22 with NEO 30 facets as predictors, and .29 with NEO 30 facets and additional non-NEO scales including selfesteem and perceived social support as predictors. They interpreted their results as indicating that facets explain double the variance of factors. However, an alternative interpretation is that self-esteem and perceived social support are not personality traits in the traditional sense, and thus the adjusted r-squared comparison of .16 for factors versus .22 (i.e., 37.5\% increase) for facets is a more reasonable estimate. A second example is provided in the meta-analysis of Steel et al. (2008), based on pooled correlations, which suggested very large incremental prediction for extraversion and neuroticism facets over corresponding factors. However, the authors acknowledged that the obtained estimates of incremental prediction were unreasonably large, suggesting that the process of pooling correlations across studies may have led to unreliable estimates.

In relation to PWB, to our knowledge, Siegler and Brummett (2000) provide the only facet-level analysis to date. They used data from a pre-existing study, and although this included items for the 30 NEO facets, dimensions of PWB were approximated based on available items rather than established PWB scales. The study reported facet-level correlations with the constructed indices of PWB. No estimate of incremental prediction of facets over factors was provided.

\subsection{The Current Study}

There are several problems with existing approaches to performing facet-level analysis. First, much of the broader facet-analysis literature has relied on small samples with fewer than 200 respondents, which has produced uncertain estimates of incremental prediction and increased the biasing effect that can result from having many more facets than factors as predictors. Second, methods for assessing the incremental prediction of facets have been employed without explicit articulation of the population parameter being estimated. Thus, it has been difficult to evaluate the potential bias and uncertainty in parameter estimates due to stepwise regression with different $\mathrm{p}$-entry rules, adjusted or nonadjusted r-squared, and use of only some or all factors. Third, existing research has involved different types of factor-facet comparisons. Specifically, studies vary in their use of facet-level test inventories, the number of Big 5 factors included, and their inclusion of variables that are arguably not personality traits. Finally, many studies have only reported zero-order correlations between facets and criteria, instead of controlling for variance explained by factors. This leads to a dramatic loss of parsimony without evidence of whether a facet-level analysis is superior.

In summary, there is a need to provide a realistic picture of the value of a facet-level analysis for understanding the relationship between personality and SWB and PWB. Some existing studies suggest that facets may explain double the variance of factors, yet the combination of methods used and minimal research suggest that this may be an overestimate, at least when limited to facets within a Big 5 inventory. 
The aim of the current study was to examine the relationship between personality and well-being, focusing particularly on the degree to which 30 personality facets provide incremental prediction of well-being over and above Big 5 personality factors. To provide a more comprehensive perspective, both subjective well-being (SWB) and psychological well-being (PWB) were examined. To provide more accurate estimates, we applied new methods for obtaining unbiased estimates and confidence intervals of incremental facet prediction.

Using a moderately large sample, we measured the Big 5 factors and 30 facets of personality, SWB, and Ryff's (1989) six dimensions of PWB. To overcome issues with previous studies, we applied methods to get both point estimates and confidence intervals for incremental prediction of facets over factors for SWB and PWB. We also assessed incremental facet prediction using semi-partial correlations controlling for the Big 5. In general, we predicted a more modest prediction of facets over factors in the range of almost none to a third more variance explained. We expected facet-level semi-partial correlations to highlight a small number of meaningful incremental facets, with a factor-level explanation capturing most of the main story.

Specifically, to overcome previous limitations, we define the parameter of interest as the population incremental variance explained, $\Delta \rho^{2}$, by facets, $\rho_{\text {(facets) }}^{2}$, over factors, $\rho_{\text {(factors) }}^{2}$. Thus, $\Delta \rho^{2}=\rho_{(\text {facets })}^{2}-\rho_{(\text {factors })}^{2}$. Since adjusted r-squared is designed to provide an unbiased estimate of $\rho^{2}$, we recommend using $R_{\text {adj(facets) }}^{2}-R_{\text {adj(factors) }}^{2}$ as the estimator for $\Delta \rho^{2}$. We use a double-adjusted-r-squared bootstrap procedure for providing confidence intervals on the incremental population prediction of facets. Finally, we examine semipartial correlations between facets and criteria, where facets are adjusted for factors, in order to assess incremental contribution of facets in a more parsimonious way than only reporting zero-order correlations.

In addition to the facet-level analysis, we also examined the relationship between personality factors and well-being. We decomposed cross-correlations between personality factors and well-being in order to identify the unique profile of personality correlations for each type of well-being, thereby replicating and extending previous work by Grant et al. (2009), who included only four dimensions of PWB. We examined cross-correlations using all six PWB dimensions. In particular, we were interested in whether the unique combinations of correlations between personality factors and well-being would replicate.

\section{Method}

\subsection{Participants and Procedure}

The sampling method was based on convenience sampling and, as such, participants were mostly undergraduate psychology students drawn from two Australian universities. The final cleaned sample for this study included 337 participants (24\% male, $76 \%$ female). Ages ranged from 16 to $55(\mathrm{M}=21, \mathrm{SD}=8.8)$. The study was completed online using Inquisit 3.0 (2011). After reading a plain language statement and providing informed consent for participation, participants completed demographics, the IPIP-NEO, SWLS, PANAS, and PWB. The final sample was drawn from an initial sample of 420 participants. Participants were excluded if any of the following criteria were met: (1) they took less than 500 milliseconds to respond to 10 or more items out of the 409 personality and well-being 
items $(n=72)$, or (2) they failed to answer one or more personality or well-being items $(n=14)$.

\subsection{Instruments}

International Personality Item Pool (IPIP) Scales Measuring Constructs Similar to 30 NEO-PI-R Facet Scales. This inventory provides a measure of both Big 5 personality factors (neuroticism, extraversion, conscientiousness, agreeableness, openness) as well as 30 facets representing six facets per factor (Goldberg, 1999; Goldberg et al., 2006). The 30 facets are closely aligned with those of the 30 item NEO-PI-R (Costa \& McCrae, 2008). The IPIP measure has the advantage of being in the public domain permitting full disclosure of item content and sharing of raw data. The test is composed of 300 items, 10 items per facet, and 60 items per factor. Each item is rated on a 5-point scale measuring the degree to which it accurately describes the participant $(1=$ very inaccurate, 2 $=$ moderately inaccurate, $3=$ neither inaccurate nor accurate, $4=$ moderately accurate, $5=$ very accurate). Scales were computed as the mean of items after any required item-reversal. Initial evidence regarding the reliability and predictive validity of the IPIP scales is favorable (Goldberg, 1999). The scales have an average coefficient alpha of .80 and an average correlation with corresponding NEO-PI-R scales of .73, or .94 when corrected for attenuation due to the unreliability of the scales in each pair (Goldberg, 1999). The IPIP scales show good predictive utility for health-related criterion variables. Johnson's (2000) factor analysis (principal components) of the IPIP facet-level scales showed that a fivefactor solution accounted for $64.9 \%$ of the variance. Facets generally loaded as expected, and the five factors were clearly defined by the five sets of six facet scales, with the facet scales within a given domain showing primary loadings on the domain factor in 27 out of 30 cases.

Scales of Psychological Well-being (Ryff, 1989). This inventory measures six dimensions of PWB: positive relations, autonomy, environmental mastery, personal growth, purpose in life, and self-acceptance. Each item was rated on a 6-point Likert-style response scale $(1=$ strongly disagree, $2=$ disagree somewhat, $3=$ disagree slightly, $4=$ agree slightly, $5=$ agree somewhat, $6=$ strongly agree). Responses were scored as the mean after any required item-reversal. The 14-item per scale version was used to ensure reliability for high quality measurement. Specifically, for the 14-item version, Ryff and Essex (1992) report internal consistency alpha coefficients ranging from .86 to .93. Factor analytic evidence suggests that (a) self-acceptance and environmental mastery are closely related to traditional SWB measures, (b) personal growth, positive relations with others and purpose in life share a higher order factor, and (c) autonomy is more distinct, being more related to variables concerned with power and control (Ryff, 1989).

Satisfaction with Life Scale (Diener, Emmons, Larsen, \& Griffin, 1985). This well-established 5-item scale was used to measure global life satisfaction. Each item was rated on a 7-point Likert-style response scale $(1=$ strongly disagree, $2=$ disagree, $3=$ slightly disagree, $4=$ neither agree nor disagree, $5=$ slightly agree, $6=$ agree, $7=$ strongly agree). The scale scores were computed as the mean of the items. Diener et al. (1985) reported high internal consistency and high temporal reliability for the scale. The twomonth test-retest reliability in their study was .82 with a Cronbach's alpha of .87. Item loadings ranged from .61 to .84, with a single factor accounting for $66 \%$ of the variance. In addition, the scale correlated significantly with related measures (e.g., personality, selfesteem, symptom checklist) and was uncontaminated by social desirability. 
Positive and Negative Affectivity Schedule (PANAS; Watson, Clark, \& Tellegen, 1988). The PANAS consists of two subscales that measure positive and negative affect. In the current study, the instrument was administered using "past few weeks" time instructions. Participants rated the extent to which they had experienced each of 20 emotions over the past few weeks on a 5-point scale $(1=$ very slightly or not at all, $2=\mathrm{a}$ little, 3 = moderately, $4=$ quite a bit, $5=$ extremely). Scales were scored as the mean of the items. Watson et al. (1988) reported that reliabilities (Cronbach's alpha) were within an acceptable range for both positive and negative affect (.86 to .90) and were unaffected by the time instructions used. Both subscales demonstrated satisfactory test-retest reliability over a two-month period. The same authors reported a low (negative) correlation between positive and negative affect, with adjectives loading on the appropriate factor. The subscales showed good external validity, correlating significantly with measures of anxiety, depression, and distress.

\subsection{Data Analysis}

Data was analyzed using R 3.0.1 (R Core Team, 2013). In the interests of reproducible research, all code used to perform the analysis and all data and metadata is available from figshare.com (Analysis for "Predicting Psychological and Subjective WellBeing"; http://dx.doi.org/10.6084/m9.figshare.972885 ).

\section{Results}

\subsection{Descriptive Statistics, Reliabilities, and Factor Analysis}

Table 1 and Table 2 report descriptive statistics and reliability for all scales used in the study. Reliability was generally very good with mean Cronbach's alpha of .81 for personality factors, .80 for personality facets, and .88 for well-being scales.

Table 1

Descriptive Statistics and Cronbach's Alpha Reliability for Personality Factors and WellBeing Scales

\begin{tabular}{lccc}
\hline Variable & $\alpha$ & $\mathrm{M}$ & $\mathrm{SD}$ \\
\hline Neuroticism & .85 & 2.91 & 0.59 \\
Extraversion & .84 & 3.37 & 0.54 \\
Openness & .72 & 3.64 & 0.41 \\
Agreeableness & .79 & 3.64 & 0.45 \\
Conscientiousness & .84 & 3.49 & 0.51 \\
Satisfaction with Life & .88 & 4.47 & 1.44 \\
Positive Affect & .89 & 3.47 & 0.79 \\
Negative Affect & .87 & 2.21 & 0.80 \\
Positive Relations & .89 & 4.42 & 0.90 \\
Autonomy & .85 & 4.08 & 0.83 \\
Environmental Mastery & .88 & 4.07 & 0.87 \\
Personal Growth & .86 & 4.85 & 0.69 \\
Purpose in Life & .89 & 4.36 & 0.91 \\
Self-Acceptance & .94 & 4.06 & 1.07 \\
\hline
\end{tabular}


Table 2

Descriptive Statistics and Cronbach's Alpha Reliability for Personality Facets

\begin{tabular}{lccc}
\hline Variable & $\alpha$ & $\mathrm{M}$ & $\mathrm{SD}$ \\
\hline N1: Anxiety & .83 & 3.10 & 0.73 \\
N2: Anger & .88 & 2.85 & 0.80 \\
N3: Depression & .90 & 2.61 & 0.88 \\
N4: Self-consciousness & .83 & 2.94 & 0.77 \\
N5: Immoderation & .77 & 3.24 & 0.70 \\
N6: Vulnerability & .85 & 2.73 & 0.75 \\
E1: Friendliness & .88 & 3.60 & 0.78 \\
E2: Gregariousness & .87 & 3.32 & 0.84 \\
E3: Assertiveness & .84 & 3.24 & 0.74 \\
E4: Activity Level & .72 & 3.01 & 0.57 \\
E5: Excitement Seeking & .82 & 3.30 & 0.72 \\
E6: Cheerfulness & .82 & 3.75 & 0.67 \\
O1: Imagination & .82 & 3.73 & 0.71 \\
O2: Artistic Interests & .75 & 3.96 & 0.62 \\
O3: Emotionality & .77 & 3.76 & 0.62 \\
O4: Adventurousness & .76 & 3.47 & 0.59 \\
O5: Intellect & .79 & 3.70 & 0.64 \\
O6: Liberalism & .65 & 3.21 & 0.60 \\
A1: Trust & .85 & 3.43 & 0.70 \\
A2: Morality & .77 & 3.85 & 0.62 \\
A3: Altruism & .79 & 4.03 & 0.57 \\
A4: Cooperation & .75 & 3.55 & 0.67 \\
A5: Modesty & .80 & 3.28 & 0.70 \\
A6: Sympathy & .73 & 3.68 & 0.59 \\
C1: Self-Efficacy & .80 & 3.69 & 0.57 \\
C2: Orderliness & .84 & 3.33 & 0.78 \\
C3: Dutifulness & .69 & 3.94 & 0.50 \\
C4: Achievement Striving & .84 & 3.67 & 0.70 \\
C5: Self-Discipline & .89 & 3.01 & 0.83 \\
C6: Cautiousness & & &
\end{tabular}

Exploratory factor analysis was performed on facet scale scores to examine whether the 30 facets loaded on the proposed five factors. Five factors were extracted using maximum likelihood estimation with Promax rotation. Overall, the factor solution showed good correspondence to the theorized structure. There was a clear drop in the scree plot after five factors and the parallel analysis also suggested five factors. Five factors explained $58.9 \%$ of the variance. Of the 30 facets, 28 facets loaded above .35 , and 25 loaded maximally on their theorized factor. Out of the 120 cross-loadings of facets on non- 
theorized factors, only $12(10 \%)$ loaded above .35 . Prominent cross-loadings included selfconsciousness (-.51), trust (.56), and altruism (.50) on extraversion; activity level (.59) on conscientiousness; dutifulness (.51) on agreeableness; and emotionality (.51) on neuroticism.

\subsection{Correlations between Big 5 Personality and Well-Being}

The full correlation matrix between factors, facets, and well-being measures is available from the online repository mentioned in the Method. Table 3 shows the correlations between personality factors and well-being scales. To better understand the cross-correlations between personality factors and well-being, a decomposition was performed. First, neuroticism and negative affect were reversed, so that all variables were positively framed. Second, cross-correlations were obtained between personality factors and well-being variables denoted by $r_{i j}$ where $i=1, \square, I$, and $j=1, \square, J$ indexing the $I=5$ personality factors and $J=9$ well-being variables respectively. Then, the overall average cross-correlation was obtained as

$$
\bar{r}=\frac{1}{I J} \square_{i} \square_{j} r_{i j}
$$

as well as the average deviation for cross-correlations for each well-being variable

and

$$
\bar{r}_{. j}=\frac{1}{I} \square_{i} r_{i j}
$$

$$
\begin{aligned}
& \text { personality } \\
& \bar{r}_{i .}=\frac{1}{J} \square_{j} r_{i j}
\end{aligned}
$$

factor

Thus, observed correlations can be decomposed into the overall average correlation, average deviation of the personality correlations, average deviation of the well-being correlations, and a residual.

$$
r_{i j}=\bar{r}_{. .}+\left(\bar{r}_{. j}-\bar{r}_{. .}\right)+\left(\bar{r}_{i .}-\bar{r}_{. .}\right)+u_{i j}
$$

So for example, the expected correlation between openness and personal growth was the grand mean (.39) plus the deviation from the grand mean of the average openness correlation (-.16) plus the deviation from the grand mean of the average personal growth correlation (.03) which equals .26 , but the obtained correlation was .55; the residual was therefore $.55-.26=.29$. Table 4 reports this analysis. Large positive residual correlations indicate that the two variables correlate more with each other than would be expected based on how much the variables correlate generally with other variables. Thus, such correlations help to highlight the unique personality profile of each well-being variable. 
Table 3

Correlations between Big 5 Personality and Well-Being Scales

\begin{tabular}{|c|c|c|c|c|c|c|c|c|c|c|c|c|c|}
\hline Variable & 1 & 2 & 3 & 4 & 5 & 6 & 7 & 8 & 9 & 10 & 11 & 12 & 13 \\
\hline 1. Neuroticism & --- & & & & & & & & & & & & \\
\hline 2. Extraversion & -.47 & --- & & & & & & & & & & & \\
\hline 3. Openness & -.07 & .26 & --- & & & & & & & & & & \\
\hline 4. Agreeableness & -.21 & .02 & .23 & --- & & & & & & & & & \\
\hline 5. Conscientiousness & -.54 & .14 & .04 & .36 & --- & & & & & & & & \\
\hline 6. Satisfaction with Life & -.57 & .51 & .13 & .11 & .35 & --- & & & & & & & \\
\hline 7. Positive Affect & -.52 & .56 & .22 & .20 & .45 & .51 & --- & & & & & & \\
\hline 8. Negative Affect & .76 & -.40 & -.06 & -.22 & -.42 & -.51 & -.35 & --- & & & & & \\
\hline 9. Positive Relations & -.48 & .58 & .25 & .38 & .28 & .55 & .43 & -.45 & --- & & & & \\
\hline 10. Autonomy & -.53 & .26 & .27 & .04 & .34 & .33 & .27 & -.49 & .32 & --- & & & \\
\hline 11. Environmental Mastery & -.75 & .56 & .13 & .22 & .60 & .69 & .58 & -.68 & .64 & .48 & --- & & \\
\hline 12. Personal Growth & -.42 & .43 & .55 & .31 & .40 & .44 & .49 & -.39 & .56 & .51 & .55 & --- & \\
\hline 13. Purpose in Life & -.58 & .50 & .25 & .28 & .65 & .63 & .62 & -.49 & .63 & .43 & .78 & .69 & --- \\
\hline 14. Self-Acceptance & -.74 & .58 & .20 & .18 & .46 & .78 & .56 & -.64 & .68 & .54 & .80 & .60 & .76 \\
\hline
\end{tabular}

Note. $|r| \geq .11$ indicates $\mathrm{p}<.05 ;|r| \geq .15$ indicates $\mathrm{p}<.01$ and are bolded.

The average correlation between personality and well-being was moderately large (.39). On the well-being side, there was not a lot of variation in average correlations with personality, although autonomy was lower than the others. The average absolute crosscorrelation was larger for psychological well-being scales (.41) than for subjective wellbeing scales (.36). In terms of personality, the common ordering emerged of neuroticism being most important by some margin followed by extraversion and conscientiousness, and then with much weaker average cross-correlations for openness and agreeableness. In addition to these general patterns, there were several notable residual cross-correlations shown in Table 4. For example, the following correlated substantially more than was implied by average cross-correlations for constituent variables: personal growth with openness, positive relations with agreeableness, neuroticism with negative affect, and purpose in life with conscientiousness. Interestingly, there were several negative residual cross-correlations: openness with negative affect, personal growth with neuroticism, environmental mastery with openness, and positive relations with conscientiousness. Thus, for example, the profile of correlations for positive relations indicates stronger relations with agreeableness and weaker relations with conscientiousness than is typically the case for well-being variables. 
Table 4

Decomposition of Cross-Correlations between Well-Being and Big 5 Personality

\begin{tabular}{|c|c|c|c|c|c|c|}
\hline & \multicolumn{5}{|c|}{ Personality } & \multirow{2}{*}{$\begin{array}{r}\text { Mean Well-Being } \\
\text { Deviation }\end{array}$} \\
\hline & N- & $\mathrm{E}$ & $\mathrm{O}$ & A & $\mathrm{C}$ & \\
\hline & \multicolumn{5}{|c|}{ Residual Correlations } & \\
\hline Satisfaction with Life & .04 & .08 & -.04 & -.04 & -.03 & -.06 \\
\hline Positive Affect & -.07 & .08 & -.01 & -.01 & .02 & .00 \\
\hline Reversed Negative Affect & .19 & -.06 & -.15 & .02 & .00 & -.02 \\
\hline Positive Relations & -.12 & .10 & .02 & .17 & -.16 & .00 \\
\hline Autonomy & .04 & -.12 & .14 & -.08 & .01 & -.10 \\
\hline Environmental Mastery & .09 & .02 & -.16 & -.06 & .10 & .06 \\
\hline Personal Growth & -.21 & -.09 & .29 & .07 & -.07 & .03 \\
\hline Purpose in Life & -.07 & -.05 & -.04 & .01 & .15 & .06 \\
\hline Self-Acceptance & .10 & .06 & -.06 & -.08 & -.02 & .04 \\
\hline Mean Personality & & 0 & 16 & 18 & 05 & $39^{\mathrm{a}}$ \\
\hline
\end{tabular}

Note. Mean deviations are the average cross-correlation for cross-correlations containing the focal variable minus the overall mean of cross-correlations. Residual correlations equal the actual cross-correlation minus the correlation predicted by summing the overall mean cross-correlations and the two mean deviations for the constituent variables. Absolute residual cross-correlations greater than or equal to 0.15 are bolded.

${ }^{a}$ Overall mean cross-correlations between personality and well-being variables

\section{3. $\quad$ Facet-level correlations with Well-Being}

Table 5 reports zero-order correlations between personality facets and well-being scales. and semi-partial correlations between personality facets and well-being scales (see parentheses), where facets have been adjusted for their shared variance with personality factors. The zero-order correlations present a complex pattern with many large correlations often consistent with patterns at the factor-level. The semi-partial correlations focus purely on the incremental prediction of facets over factors. Notable semi-partial correlations are depression with satisfaction with life $(r=-.28)$, positive relations $(r=-.20)$, purpose in life $(r=-.24)$, and self-acceptance $(r=-.37)$; self-consciousness with autonomy $(r=.20)$; assertiveness with autonomy $(r=.18)$; excitement seeking with positive relations $(r=-.19)$; cheerfulness with satisfaction with life $(r=.26)$, cooperation with autonomy $(r=-.19)$; and achievement striving with purpose in life $(r=.21)$. The table also reports the proportion of variance in the facet that is not explained by factors. The mean proportion of unique variance was 35.6 percent. 


\section{Table 5}

Zero-Order Correlations between Facets and Well-being (Semi-partial Correlations with Variance Explained by Factors Removed from Facets Shown in Parentheses)

\begin{tabular}{|c|c|c|c|c|c|c|c|c|c|c|c|}
\hline & SWL & PA & NA & PR & $\mathrm{AU}$ & EM & PG & PL & SA & Uniqu & \\
\hline N1: Anxiety & $-.47(.02)$ & $-.39(.00)$ & $.64(-.01)$ & $-.35(.07)$ & $-.41(.06)$ & -.58 & -.29 & $-.38(.05)$ & $-.57(.09)$ & .21 & .03 \\
\hline N2: Anger & $-.31(.05)$ & $-.29(-.03)$ & $.54(-.02)$ & $-.27(.08)$ & $-.25(.17)$ & $-.43(.05)$ & $-.22(.04)$ & $-.30(.04)$ & $-.39(.13)$ & .33 & .06 \\
\hline N3: Depression & $-.67(-.28)$ & $-.56(-.09)$ & $.70(.12)$ & $-.59(-.20)-$ & $-.45(-.03)$ & $-.76(-.14)$ & $-.48(-.13)$ & $-.70(-.24)$ & $-.86(-.37)$ & .27 & -.18 \\
\hline N4: Self-consciousness & $-.46(.14)$ & $-.45(.11)$ & $.56(-.02)$ & $-.47(-.02)-$ & $-.53(-.20)$ & -.59 & $-.40(-.01)$ & $-.48(.05)$ & $-.63(.04)$ & .24 & .02 \\
\hline N5: Immoderation & $-.16(.09)$ & $-.16(.05)$ & $.32(-.09)$ & $-.07(.07)$ & $-.29(.01)$ & $-.32(.07)$ & $-.10(.12)$ & $-.24(.12)$ & $-.24(.10)$ & .49 & .08 \\
\hline N6: Vulnerability & $-.49(.00)$ & $-.46(-.03)$ & $.65(.03)$ & $-.37(.02)-$ & $-.49(-.04)$ & $-.68(-.08)$ & $-.37(-.02)$ & $-.50(-.01)$ & $-.61(.04)$ & .27 & -.02 \\
\hline E1: Friendliness & $.44(-.03)$ & $.49(-.03)$ & $-.41(.00)$ & $.67(.17)$ & $.22(-.02)$ & $.55(.04)$ & $.37(-.07)$ & $.49(.04)$ & $.56(.03)$ & .23 & .01 \\
\hline E2: Gregariousness & $.34(-.05)$ & $.34(-.11)$ & $-.27(-.01)$ & $.46(-.01)$ & $.03(-.15)$ & $.36(-.04)$ & $.19(-.12)$ & $.28(-.06)$ & $.37(-.07)$ & .27 & -.07 \\
\hline E3: Assertiveness & $.39(-.08)$ & $.46(-$ & $-.31(.03)$ & $.39(.01)$ & $.39(.18)$ & $.48(-$ & $.41(.10)$ & $.45(.00)$ & $.50(.01)$ & .29 & .01 \\
\hline E4: A & .33( & .49( & $-.30(.01)$ & .35( & .26( & .51 & .38 & .53( & .44 & .55 & .03 \\
\hline E5: $\mathrm{E}$ & .21( & $.23($. & $-.08($. & .15 (-.19) & $.05(-$ & .10( & $.15(-$ & .04( & .16( & .38 & -.08 \\
\hline E6: ( & .57( & .52 & $-.41(-$. & .57 & .25 & .54 & .46 & .49 & .59 & .30 & .11 \\
\hline O1: I & $.06(.07)$ & .07 & $.06($. & $.07(-$ & $.08(-$. & -.04 & $.25(-.09)$ & $.04(-.02)$ & .02( & .41 & -.02 \\
\hline Interests & $.06(-.01)$ & $.19(.06)$ & $-.05(-$. & $.16(-$ & & .05( & $.32(-$ & $.16(-$ & .13 & .54 & -.03 \\
\hline O3: $\mathrm{E}$ & $.01(.04)$ & $.13(.02)$ & $.16(.03)$ & $.25(.14)$ & $.10(.14)$ & -.01 & $.41(.12)$ & $.22(.12)$ & .08( & .40 & .08 \\
\hline iturousness & $.27(-.01)$ & $.29(-.02)$ & $-.27(.01)$ & $.30(-.07)$ & $.27(-.04)$ & $.31(.00)$ & $.51(.11)$ & $.32(.02)$ & $.34(-$ & .53 & .00 \\
\hline O5: Inte & $.18(-.06)$ & $.25(-.04)$ & $-.19(.0$ & $.21(.00)$ & $.44(.14)$ & .31( & $.50(.05)$ & $.33(-$ & $.26(-$ & .45 & .00 \\
\hline O6: Liberalism & $-.10(-.03)$ & $-.08(-.03)$ & $.06(-.04)$ & $-.02(.02)$ & $.07(-.02)$ & $-.10(.03)$ & $.13(-.07)$ & $-.06(-.02)$ & $-.04(.02)$ & .60 & -.01 \\
\hline A1: Trust & $.35(.05)$ & $.36(.01)$ & $-.38(.00)$ & $.59(.14)$ & $.13(-.06)$ & $.44(.05)$ & $.37(.01)$ & $.39(.03)$ & $.45(.07)$ & .43 & .03 \\
\hline A2: Morality & $.05(-.02)$ & $.09(-.07)$ & $-.20(-.06)$ & $.21(-.03)$ & $.08(.11)$ & $.22(.07)$ & $.18(-.02)$ & $.28(.06)$ & $.15(.07)$ & .31 & .02 \\
\hline A3: Altruism & $.26(-.01)$ & $.41(.07)$ & $-.24(.07)$ & $.52(.03)$ & $.15(.04)$ & $.37(-.02)$ & $.47(.07)$ & $.45(.02)$ & $.35(.02)$ & .24 & .02 \\
\hline $\mathrm{A} 4: \mathrm{C}$ & $.07(.03)$ & $.08(.00)$ & $-.22(-.03)$ & $.17(-.07)$ & $-.06(-.19)$ & $.13(-.04)$ & $.14(-.06)$ & $.17(-.01)$ & $.11(.00)$ & .33 & -.03 \\
\hline A5: 1 & $-.32(-$. & $-.22($. & .14 & & -.15 & -.26 & & -.24( & $-.38(-$ & .43 & -.04 \\
\hline A6: $\mathrm{S}$ & $.09(.07)$ & $.14(.00)$ & $-.01(.09)$ & $.33(.04)$ & $.03(.02)$ & $.05(-.07)$ & $.36(.06)$ & $.20(.01)$ & .11( & .32 & .01 \\
\hline C1: Self-Efficacy & $.49(.02)$ & $.51(-.05)$ & $-.52(.01)$ & $.44(.07)$ & $.53(.14)$ & $.70(.05)$ & $.56(.11)$ & $.70(.07)$ & $.64(.06)$ & .26 & .05 \\
\hline $\mathrm{C} 2$ : Orderliness & $.07(-.09)$ & $.22(.01)$ & $-.17(-.02)$ & $.02(-.05)$ & $.06(-.10)$ & $.25(-.09)$ & $.11(-.05)$ & $.30(-.12)$ & $.13(-.06)$ & .36 & -.06 \\
\hline C3: Dutifulness & $.14(-.09)$ & $.25(-.07)$ & $-.26(.01)$ & $.22(-.05)$ & $.23(.11)$ & $.37(-.01)$ & $.28(-.02)$ & $.41(-.06)$ & $.26(-.01)$ & .35 & -.02 \\
\hline C4: Achievement Striving & $.42(.13)$ & $.54(.16)$ & $-.31(.07)$ & $.30(.01)$ & $.33(.04)$ & $.57(.04)$ & $.47(.12)$ & $.72(.21)$ & $.48(.08)$ & .29 & .08 \\
\hline C5: Self-Discipline & $.41(.05)$ & $.49(.08)$ & $-.44(.00)$ & $.27(-.04)$ & $.30(-.12)$ & $.62(.05)$ & $.34(-.06)$ & $.60(-.02)$ & $.47(-.03)$ & .25 & -.01 \\
\hline C6: Cautiousness & $.06(-.01)$ & $.03(-.15)$ & $-.22(-.05)$ & $.05(.08)$ & $.17(.01)$ & $.23(-.01)$ & $.11(-.06)$ & $.26(-.04)$ & $.12(-.01)$ & .35 & -.02 \\
\hline
\end{tabular}

Note. $\mathrm{SWL}=$ Satisfaction with life, $\mathrm{PA}=$ Positive affect, $\mathrm{NA}=$ Negative affect, $\mathrm{PR}=$ Positive relations, $\mathrm{AU}=$ Autonomy, $\mathrm{EM}=$ Emotional mastery, $\mathrm{PG}=$ Personal growth, $\mathrm{PL}=$ Purpose in life, $\mathrm{SA}=$ Self-acceptance.

Significant semi-partial correlations $(\mathrm{p}<.001)$ are bolded.

${ }^{\text {a }}$ Proportion of personality variance not predicted by Big 5 factors of personality. b Average semi-partial correlation for facet across well-being variables, where negative affect has been reversed. 


\subsection{Prediction of Well-Being from Personality Factors and Facets}

A set of linear multiple regressions (direct entry) was conducted predicting each well-being variable using the Big 5 as predictors. Table 6 reports the obtained standardized regression coefficients. Table 7 reports the corresponding estimate of population variance explained (i.e., $R_{\text {adj }}^{2 \text { (factors) }}$. In general, the Big 5 explained substantial variance. In all cases, the Olkin-Pratt formula for adjusted r-squared was used as it aligns with the assumption that the predictor variables are a random sample from a population. Average $R_{\text {adj }}^{2 \text { (factors) was }}$ .55 for PWB variables and .48 for SWB variables.

Table 6

Standardized Regression Coefficients Predicting Well-Being Scales from Big 5 Personality

\begin{tabular}{llllll}
\hline DV & \multicolumn{5}{c}{ Standardized Beta } \\
\cline { 2 - 6 } & $\mathrm{N}$ & $\mathrm{E}$ & $\mathrm{O}$ & $\mathrm{A}$ & $\mathrm{C}$ \\
\hline Satisfaction with Life & $\mathbf{- . 3 7}$ & $\mathbf{. 3 1}$ & .02 & -.01 & .11 \\
Positive Affect & -.14 & $\mathbf{. 4 3}$ & .08 & .03 & $\mathbf{. 3 1}$ \\
Negative Affect & $\mathbf{. 7 1}$ & -.07 & .03 & -.07 & .00 \\
Positive Relations & $\mathbf{- . 1 8}$ & $\mathbf{. 4 9}$ & .03 & $\mathbf{. 3 3}$ & -.01 \\
Autonomy & $\mathbf{- . 5 1}$ & -.07 & $\mathbf{. 2 9}$ & $\mathbf{- . 1 8}$ & .13 \\
Environmental Mastery & $\mathbf{- . 4 2}$ & $\mathbf{. 3 1}$ & .00 & .01 & $\mathbf{. 3 2}$ \\
Personal Growth & $\mathbf{- . 1 3}$ & $\mathbf{. 2 1}$ & $\mathbf{. 4 5}$ & .08 & $\mathbf{. 2 5}$ \\
Purpose in Life & $\mathbf{- . 1 3}$ & $\mathbf{. 3 3}$ & $\mathbf{. 1 3}$ & .03 & $\mathbf{. 5 2}$ \\
Self-Acceptance & $\mathbf{- . 5 2}$ & $\mathbf{. 2 9}$ & .09 & .00 & $\mathbf{. 1 4}$
\end{tabular}

Note. Significant coefficients $(\mathrm{p}<.01)$ are bolded.

Table 7 reports the adjusted r-squared predicting each well-being scale, first with the five personality factors as predictors, and then with the 30 personality facets as predictors. Estimates of incremental population variance explained, $\Delta \rho^{2}$, were obtained by subtracting $R_{\text {adj }}^{2}$ for factors from $R_{\text {adj }}^{2}$ for facets. Confidence intervals were obtained using a double-adjusted-r squared bootstrap method. This method involves first sampling with replacement from the data to generate $K$ bootstrap samples of equal size as the raw data. For each bootstrap sample, $R_{(\text {factors })}^{2}$ and $R_{(\text {facets })}^{2}$ is obtained. Then for both $R^{2}$ values, the formula for adjusted r-squared is applied twice

$$
\tilde{R}_{\text {adj }}^{2}=f\left(f\left(R^{2}\right)\right)
$$

where $f($.$) is the formula for adjusted r-squared. The adjustment formula is applied twice,$ first to adjust for the bias associated with the bootstrap treating the sample as the population, and second to adjust for the standard bias in estimating $\rho^{2}$ from sample data. Finally the estimate is obtained for the particular bootstrap sample as $\Delta \hat{\rho}^{2}=\tilde{R}_{\text {adj(facets) }}^{2}-\tilde{R}_{\text {adj(factors) }}^{2}$. To obtain 95 percent confidence intervals, the .025 and .975 sample quantiles are obtained from the $\mathrm{K}$ bootstrap estimates. 
Table 7

Variance Explained in Well-Being Scales by Big 5 Personality and 30 Facets of Personality

\begin{tabular}{llll}
\hline DV & $R_{\text {adj }}^{2 \text { (factors) }}$ & $R_{\text {adj }}^{2 \text { (facets) }}$ & $\Delta \hat{\rho}^{2}(95 \% \mathrm{CI})$ \\
\hline Satisfaction with Life & .40 & .52 & $.12(.06$ to .18$)$ \\
Positive Affect & .47 & .51 & $.04(.00$ to .09$)$ \\
Negative Affect & .58 & .59 & $.01(.00$ to .05$)$ \\
Positive Relations & .50 & .57 & $.07(.02$ to .13$)$ \\
Autonomy & .36 & .50 & $.14(.07$ to .21$)$ \\
Environmental Mastery & .68 & .73 & $.04(.01$ to .08$)$ \\
Personal Growth & .51 & .59 & $.07(.02$ to .13$)$ \\
Purpose in Life & .62 & .72 & $.11(.07$ to .15$)$ \\
Self-Acceptance & .63 & .78 & $.15(.10$ to .20$)$ \\
\hline
\end{tabular}

Note. $\Delta \hat{\rho}^{2}=R_{\text {adj }}^{2 \text { (facets) }}-R_{\text {adj }}^{2 \text { (factors) }}$

The mean ratio of facets to factors adjusted r-squared was 1.17 . The mean $\Delta \hat{\rho}^{2}$ was .08. In general, $\Delta \hat{\rho}^{2}$ was larger for psychological well-being (mean $\Delta \hat{\rho}^{2}=.10$ ) than for subjective well-being (mean $\Delta \hat{\rho}^{2}=.06$ ). In particular, negative affect, which correlated very highly with neuroticism, showed minimal incremental facet prediction. Positive affect and environmental mastery showed small amounts of incremental facet prediction. Autonomy and self-acceptance showed the largest amounts of incremental facet prediction.

\section{Discussion}

This study aimed to examine the relationship between personality and well-being. In particular, it examined the incremental prediction of personality facets over Big 5 factors. In general, personality and well-being showed substantial correlation. Facets accounted for additional population variance in well-being but the increase was often modest, ranging from almost no additional variance explained to around a third more variance explained. The subsequent discussion elaborates, first, on factor-level relationships, then on facet-level relationships, and finally on broader theoretical and methodological issues.

\subsection{Well-being and the Big 5}

There were several general patterns in the cross-correlations between Big 5 personality and well-being. First, neuroticism was clearly the largest and most consistent correlate of well-being; then came extraversion, closely followed by conscientiousness. These findings are generally consistent with DeNeve and Cooper (1998) and Steel et al. (2008), whose meta-analytic studies focused on subjective well-being, and are consistent with Grant et al. (2009) and Keyes et al. (2002). While agreeableness and openness still had meaningful correlations, these were less consistent and generally smaller. Second, PWB dimensions showed a slightly stronger relationship with the Big 5 than did SWB dimensions. Butkovic et al. (2012) likewise reported that personality explained more variance in PWB than SWB. Third, consistent with Schmutte and Ryff (1997), PWB showed a more diverse relationship with personality than did SWB. In broad terms, SWB dimensions were often well predicted by neuroticism and extraversion, whereas agreeableness, openness, and conscientiousness were important correlates of several PWB 
dimensions (c.f. Grant et al., 2009). In addition, residual cross-correlations and standardized betas highlighted several relationships between PWB and the Big 5 that shed light on the nature of the PWB construct contributing to broader discussion regarding the meaning of PWB (e.g., Ryff \& Singer, 1998, 2006). These points are elaborated in more detail below. Taken together, the results reinforce the notion that the key dispositional influences on well-being vary across well-being dimensions (Grant et al., 2009).

There were no significant residual cross-correlations for SWL, indicating that there were no personality variables that correlated more strongly with SWB than expected based on their correlations with other well-being variables. Neuroticism had the strongest standardized beta for SWL, which was also predicted by extraversion and to a lesser extent conscientiousness. In contrast, extraversion was the strongest predictor of PA, which was also predicted by conscientiousness and neuroticism. There were no significant residual cross-correlations for PA, but neuroticism and openness showed significant residual crosscorrelations for NA. Neuroticism was the only significant predictor of NA. The finding that SWB dimensions were well predicted by neuroticism and extraversion is consistent with meta-analytic studies (DeNeve \& Cooper, 1998; Steel et al., 2008).

Personal growth had a positive residual cross-correlation with openness and a negative residual cross-correlation with neuroticism. Bardi and Ryff (2007) similarly reported that individuals who were higher on openness and lower on neuroticism reported higher personal growth. Standardized betas showed that personal growth was predicted by all five traits, with openness emerging as the strongest predictor. This strong relationship between personal growth and openness is consistent with Schmutte and Ryff (1997). Personal growth items include the perception that the individual is growing, a belief that change is possible, and valuing of change (Ryff, 1989). Thus, beyond the pure well-being elements, the measure of personal growth also captures a disposition to the concept that growth and change is positive, which helps to explain the relationship with openness. Arguably, these more attitudinal elements go beyond pure well-being and actually suggest a humanistic value system regarding what is the good life.

Autonomy was one of the least well-predicted well-being dimensions. There were no significant residual cross-correlations for this dimension, although standardized betas indicated that the dimension was predicted by greater openness and conscientiousness and less neuroticism and agreeableness, with neuroticism being the strongest predictor. Previous studies have also primarily identified an association between autonomy and agreeableness or neuroticism (Grant et al., 2009; Schmutte \& Ryff, 1997), perhaps reflecting the focus of autonomy items on a lack of care for what others think or low selfconsciousness. However, there is also arguably an implicit assumption that autonomy involves some degree of independent thinking. Items capture self-confidence and as well as a spectrum of not being excessively influenced by others to more extreme independence of thought. Emotional stability (the inverse of neuroticism) and antagonism (the inverse of agreeableness) capturinquie elements of self-confidence and independent thinking respectively. A readiness to not conform can go against being agreeable. The Ryff scale measures a relatively social conception of autonomy. While much of the autonomy construct captures positive aspects, there is an aspect that might actually result in less wellbeing. For instance, not listening to the views of others, never sacrificing one's needs for the needs of others, or an inability to accept the rituals and values of a society could have a range of negative consequences. Similarly, some individuals may place less value on 
independence of thought thereby further reducing the relationship between autonomy and well-being.

Positive relations had a positive residual cross-correlation with agreeableness and a negative residual cross-correlation with conscientiousness and it was predicted particularly by extraversion, agreeableness and neuroticism. Items for positive relations capture not only whether a person has good friends, but also whether the person values interactions with others and sees him or herself as capable of being a good friend. In this sense, extraversion relates to both social engagement and a desire to be social, and agreeableness captures many aspects related to being friendly and accommodating. Consistent with this, previous studies have primarily linked positive relations to agreeableness and extraversion (Grant et al., 2009; Schmutte \& Ryff, 1997). However, the Ryff measure of positive relations goes beyond measuring presence of or satisfaction with interpersonal relationships, also measuring evaluative judgments about the importance of friendship and skills in friendship formation, suggesting that other personality dimensions are also important. Indeed, Siegler and Brummett (2000) linked positive relations with select facets of all Big 5 traits.

Purpose in life had a strong positive residual cross-correlation with conscientiousness. Conscientiousness also had the strongest standardized beta, followed by extraversion while neuroticism and openness showed a weaker relationship with purpose in life. The strong association between purpose in life and conscientiousness is consistent with previous work (Grant et al., 2009; Schmutte \& Ryff, 1997), and others have also documented the associations between this dimension and extraversion and neuroticism (Schmutte \& Ryff, 1997; Siegler \& Brummett, 2000). Purpose in life items focus on having longer term projects, getting pleasure from moving towards goals, and aspects of life satisfaction.

Self-acceptance and environmental mastery tended to have similar patterns to satisfaction with life, with significant betas for neuroticism, extraversion and conscientiousness (self-acceptance was also predicted by openness, though to a lesser extent). Environmental mastery had a significant residual cross-correlation with openness; there were no significant residual cross-correlations for self-acceptance. Both of these PWB dimensions have been flagged (Bouchard Jr \& Loehlin, 2001) as more reflective of SWB than PWB. Self-acceptance items largely focus on self-esteem, positive comparison of self versus others, and elements of life satisfaction. Environmental mastery focuses on a sense control, with elements of life satisfaction.

It is noteworthy that the Big Five predicted self-acceptance and environmental mastery more strongly than they predicted satisfaction with life. Once again, this is consistent with previous work supporting a stronger relationship between personality and well-being for PWB than SWB (Butkovic et al., 2012; Grant et al., 2009) and reinforces the distinctiveness of these dimensions.

At present, the Ryff scales seem to incorporate more than just whether the wellbeing aspects are present; they also embody a range of assumptions about what constitutes the good life. Of course, psychological theory underpins the importance of such dimensions, but each dimension captures a unique flavor of the concept of PWB and also seems to measure the degree to which that dimension is characteristically valued by the individual. Thus, open people may search for personal growth. Disagreeable people may be more willing to assert their opinion in defiance of what a group thinks. And conscientious 
people may value purpose in life and seek to achieve projects and plans. While any measure of well-being will have a particular orientation, there is a risk of imposing a humanistic value system on to people by labeling such dimensions as well-being rather than using the more theoretically neutral SWB dimensions.

\subsection{Incremental Prediction of Well-Being by Facets}

Overall, personality facets provided a meaningful increase in the variance explained in well-being over and above the personality factors. However, there was no doubling of explained variance as eluded to in the extant literature (see Quevedo \& Abella, 2011). Instead, increases ranged from almost nothing to around a third more. Well-being dimensions varied substantially in the size of this increase. Positive and negative affect both showed minimal increases, which is inconsistent with the very large incremental prediction achieved for facets over factors for some traits in meta-analytic research (Steel et al., 2008). In contrast, self-acceptance, autonomy, satisfaction with life, and purpose in life showed fairly large increases. However, this is the first study to estimate the incremental prediction of facets over factors for PWB and the results await replication. Furthermore, the cause of the variation in incremental variance is not entirely clear and warrants exploration in future research.

Examination of the semi-partial correlations between facets and well-being helped to explain the incremental prediction by facets. For example, autonomy was associated with more anger and assertiveness, and less with self-consciousness, cooperation, and gregariousness, reinforcing the above notion that this dimension reflects the degree of importance placed on what others think and independent thought. Purpose in life had a strong link with achievement striving, reinforcing the goal-directed emphasis of this dimension. More generally, depression and cheerfulness emerged as incremental correlates for many well-being variables. In many cases, these correlates seemed to be related to overlap in the conceptual nature of the constructs (for further discussion of construct overlap in this context, see Schmutte \& Ryff, 1997).

Overall, the bootstrapping and the semi-partial correlations helped to explain the incremental contribution of facets. First, bootstrapping highlighted the uncertainty around estimates of incremental variance explained. While the size of the confidence intervals varied, the sample size of approximately 300 was sufficient for $95 \%$ confidence intervals to provide a good understanding of the 'ball park' of the effect size. Also, the semi-partial correlations helped to yield a more parsimonious view of the incremental role of facets. Compared to zero-order correlations, semi-partial correlations flagged only a select few facets, taking factor correlations as a starting point and presenting a more parsimonious view. Compared to stepwise regression, the results were less binary in terms of inclusion of predictors.

\subsection{Incremental Facet Prediction}

Conclusions about incremental facet prediction in the present study are based on the inclusion of nested facets. As Quevedo and Abella (2011) found, inclusions of non-nested facets can substantially increase the incremental prediction of facets. There are several reasons for this. First, by construction, factors capture some of the variance of nested facets. So for instance, when comparing facets to the Big 5 from a given test, incremental prediction should be greater when facets come from a different test. However, by taking facets from a different test, some of the incremental variance would be obtained by the slightly different measurement of the Big 5. Second, the selection of facets in a personality 
test may be partially constrained by the need to fit within a Big 5 theoretical framework. Thus, personality traits not captured by the Big 5 might be omitted. However, alternatively, there is the potential to include variables that are not typically considered personality traits, or that get even closer to well-being related constructs.

This raises questions about what is a natural or useful way of framing incremental prediction of well-being from personality facets. It also relates to issues of how personality tests should be constructed in order to both reliably measure the Big 5 but also capture diverse facets that assist with incremental prediction. At the very least, it is necessary to be clear when describing estimates of incremental prediction as to what class of facets is being included.

Overall, the results of this study support the value of a facet-level analysis, but suggest that the contribution is more modest than some previous studies have suggested. The increases in estimated population prediction seen in this study are of a magnitude that justifies the increased complexity. Furthermore, in contrast to the complexity of zero-order correlation matrices, the semi-partial correlation analysis helps to provide a parsimonious picture of the relevant facets that support the incremental prediction.

\subsection{Construct Overlap and Causal Pathways}

Beyond identifying the correlations between personality and well-being, there is the broader issue of the degree to which such relationships are based on construct overlap or some form of causal relationship. Examination of item content strongly supports the idea that construct overlap explains many of the observed correlations. Neuroticism measures the tendency to experience a range of negative emotions, and clearly negative affect is almost synonymous with this tendency. In the case of extraversion, there is a mixture of items, some of which pertain directly to the experience of positive emotions whereas others pertain more to experiences that often elicit positive emotions. However, personality traits can be seen as more stable than well-being and thus as the cause of well-being. Arguments can also be made for how personality traits influence the motivation, environment, and interpretive lens of the individual, which in turn influences well-being. A recent study by Soto (2014) of the longitudinal relationship between the Big 5 and the subjective wellbeing dimensions supported the notion that personality traits and well-being dimensions influence one another reciprocally over time.

In some respects a facet-level analysis provides greater scope for both forms of prediction, but perhaps greater construct overlap is particularly likely. The Big 5 is necessarily broad, yet the chance that a well-being scale is going to overlap substantively with a specific facet scale increases. For example, depression seems to be the aspect of neuroticism that most directly relates to a wide range of well-being measures. Likewise, specific facets like achievement striving overlap substantively with valuing an orientation to life that emphasizes personal growth (Ryff \& Singer, 2006).

The research also raises issues regarding the position of PWB in the causal and definitional system that contains personality and SWB. For example, Diener et al. (2003) proposed that there are a multiple pathways to well-being that may differ between people and across cultures. Generally, environmental mastery, self-acceptance and, to some extent, purpose in life substantially overlap with satisfaction with life. Satisfaction with life seems to be the more 'pure' measure of well-being in that the individual is free to evaluate their life on their own terms. Autonomy, positive relations, and personal growth seem to capture important pathways to SWB. Even if they are viewed as an essential part of well-being, 
care is needed when designing measures to ensure attitude to the dimension is not confounded with status on the dimension.

\subsection{Conclusion, Limitations, and Future Research}

This study has provided a more complete picture of the relationship between personality, SWB, and PWB. The results provide a balance between calls that only the Big 5 is necessary and claims that facets substantially improve prediction. In addition, our methodological approach provided a parsimonious explanation to the complex patterns of cross-correlations. By making available all data and data analysis code, others are encouraged to further explore the data to generate additional insights.

In terms of limitations, the research was conducted on a young adult sample, predominantly consisting of university students. Such a sample may have particular priorities and values in life, which may have influenced the pattern of correlations observed. Clearly more research is required to explore incremental facet prediction with different personality tests, and different kinds of facets. Furthermore, while the Ryff scales have proven very useful in advancing understanding of PWB, there may be a need to further refine measures of PWB to minimize inappropriate measurement of values and unnecessary confounding with life satisfaction and related measures.

\section{References}

Bardi, A., \& Ryff, C. D. (2007). Interactive effects of traits on adjustment to a life transition. Journal of Personality, 75(5), 955-984. doi: 10.1111/j.1467-6494.2007.00462.x

Bouchard Jr, T. J., \& Loehlin, J. C. (2001). Genes, evolution, and personality. Behavior Genetics, 31(3), $243-$ 273. doi: $10.1023 / \mathrm{A}: 1012294324713$

Brickman, P., \& Campbell, D. T. (1971). Hedonic relativism and planning the good society. In M. H. Apley (Ed.), Adaptation-level theory (pp. 287-305). New York: Academic Press.

Butkovic, A., Brkovic, I., \& Bratko, D. (2012). Predicting well-being from personality in adolescents and older adults. Journal of Happiness Studies, 13(3), 455-467. doi: 10.1007/s10902-011-9273-7

Compton, W. C. (1998). Measures of mental health and a five factor theory of personality. Psychological Reports, 83(1), 371-381. doi: 10.2466/pr0.1998.83.1.371

Costa, P. T., \& McCrae, R. R. (1992). Revised NEO Personality Inventory and NEO Five Factor Inventory: professional manual (Vol. 396). Odessa: Psychological Assessment Resources.

Costa, P. T., \& McCrae, R. R. (2008). The Revised NEO Personality Inventory (NEO-PI-R). The SAGE handbook of personality theory and assessment, 2, 179-198.

Deci, E. L., \& Ryan, R. M. (2008). Hedonia, eudaimonia, and well-being: An introduction. Journal of Happiness Studies, 9(1), 1-11. doi: 10.1007/s10902-006-9018-1

DeNeve, K. M., \& Cooper, H. (1998). The happy personality: a meta-analysis of 137 personality traits and subjective well-being. Psychological Bulletin, 124(2), 197-229. doi: 10.1037/0033-2909.124.2.197

Diener, E. (1984). Subjective well-being. Psychological Bulletin, 95(3), 542-575. doi: 10.1037/00332909.95.3.542

Diener, E. (Ed.). (2009). Culture and well-being: The collected works of Ed Diener (Vol. 38). New York: Springer.

Diener, E., Emmons, R. A., Larsen, R. J., \& Griffin, S. (1985). The satisfaction with life scale. Journal of Personality Assessment, 49(1), 71-75. doi: 10.1207/s15327752jpa4901_13

Diener, E., Oishi, S., \& Lucas, R. E. (2003). Personality, culture, and subjective well-being: Emotional and cognitive evaluations of life. Annual Review of Psychology, 54(1), 403-425. doi: 10.1146/annurev.psych.54.101601.145056

Diener, E., Suh, E. M., Lucas, R. E., \& Smith, H. L. (1999). Subjective well-being: Three decades of progress. Psychological Bulletin, 125(2), 276-302. doi: 10.1037/0033-2909.125.2.276

Digman, J. M. (1997). Higher-order factors of the Big Five. Journal of Personality and Social Psychology, 73(6), 1246-1256. doi: 10.1037/0022-3514.73.6.1246

Fujita, F., \& Diener, E. (2005). Life satisfaction set point: Stability and change. Journal of Personality and Social Psychology, 88(1), 158-164. doi: 10.1037/0022-3514.88.1.158 
Goldberg, L. R. (1992). The development of markers for the Big-Five factor structure. Psychological Assessment, 4(1), 26-34. doi: 10.1037/1040-3590.4.1.26

Goldberg, L. R. (1993). The structure of phenotypic personality traits. American Psychologist, 48 (1), $26-34$. doi: 10.1037/0003-066X.48.1.26

Goldberg, L. R. (1999). A broad-bandwidth, public domain, personality inventory measuring the lower-level facets of several five-factor models. Personality Psychology in Europe, 7, 7-28.

Goldberg, L. R., Johnson, J. A., Eber, H. W., Hogan, R., Ashton, M. C., Cloninger, C. R., \& Gough, H. G. (2006). The international personality item pool and the future of public-domain personality measures. Journal of Research in Personality, 40(1), 84-96. doi: 10.1016/j.jrp.2005.08.007

Grant, S., Langan-Fox, J., \& Anglim, J. (2009). The Big Five traits as predictors of subjective and psycholoical well-being. Psychological Reports, 105(1), 205-231. doi: 10.2466/PR0.105.1.205-231

Headey, B., \& Wearing, A. J. (1992). Understanding happiness: A theory of subjective well-being. Melbourne: Longman Cheshire.

Inquisit 3.0 [Computer software]. (2012). Seattle: Millisecond Software.

John, O. P. \& Srivastava, S. (1999). The Big Five trait taxonomy: History, measurement, and theoretical perspectives. In L. A. Pervin and J. P. Oliver (Eds.), Handbook of personality: Theory and research ( $2^{\text {nd }}$ ed., pp. 102-138). New York: Guilford.

Johnson, J. A. (2000). Web-based personality assessment: Project description and rationale. Paper presented at the 71st Annual Meeting of the Eastern Psychological Asociation, Baltimore, MD.

Keyes, C. L., Shmotkin, D., \& Ryff, C. D. (2002). Optimizing well-being: The empirical encounter of two traditions. Journal of Personality and Social Psychology, 82(6), 1007-1022. doi: 10.1037/00223514.82.6.1007

Lucas, R. E., \& Diener, E. (2008). Subjective well-being. In M. Lewis, J. M. Haviland-Jones and L. Feldman Barrett (Eds.), Handbook of emotions (pp. 471-484). New York: Guilford.

Lucas, R. E., Diener, E., \& Suh, E. (1996). Discriminant validity of well-being measures. Journal of Personality and Social Psychology, 71(3), 616-628. doi: 10.1037/0022-3514.71.3.616

Lykken, D., \& Tellegen, A. (1996). Happiness is a stochastic phenomenon. Psychological Science, 7(3), 186189. doi: $10.1111 / \mathrm{j} .1467-9280.1996 . t b 00355 . x$

McCrae, R. R., \& John, O. P. (1992). An introduction to the five - factor model and its applications. Journal of Personality, 60(2), 175-215. doi: 10.1111/j.1467-6494.1992.tb00970.x

McGregor, I., \& Little, B. R. (1998). Personal projects, happiness, and meaning: On doing well and being yourself. Journal of Personality and Social Psychology, 74(2), 494-512. doi: 10.1037/00223514.74.2.494

Musek, J. (2007). A general factor of personality: Evidence for the Big One in the five-factor model. Journal of Research in Personality, 41(6), 1213-1233. doi: 10.1016/j.jrp.2007.02.003

Paunonen, S. V., \& Ashton, M. C. (2001). Big Five factors and facets and the prediction of behavior. Journal of Personality and Social Psychology, 81(3), 524-539. doi: 10.1037/0022-3514.81.3.524

Paunonen, S. V., \& Jackson, D. N. (2000). What is beyond the big five? Plenty! Journal of Personality, 68(5), 821-835. doi: 10.1111/1467-6494.00117

Quevedo, R. J. M., \& Abella, M. C. (2011). Well-being and personality: Facet-level analyses. Personality and Individual Differences, 50(2), 206-211. doi: 10.1016/j.paid.2010.09.030

R Core Team. (2013). R: A language and environment for statistical computing. Vienna: R Foundation for Statistical Computing.

Ryan, R. M., \& Deci, E. L. (2001). On happiness and human potentials: A review of research on hedonic and eudaimonic well-being. Annual Review of Psychology, 52(1), 141-166. doi: 10.1146/annurev.psych.52.1.141

Ryff, C. D. (1989). Happiness is everything, or is it? Explorations on the meaning of psychological wellbeing. Journal of Personality and Social Psychology, 57(6), 1069-1081. doi: 10.1037/00223514.57.6.1069

Ryff, C. D., \& Essex, M. J. (1992). The interpretation of life experience and well-being: the sample case of relocation. Psychology and Aging, 7(4), 507. doi: 10.1037//0882-7974.7.4.507

Ryff, C. D., \& Keyes, C. L. M. (1995). The structure of psychological well-being revisited. Journal of Personality and Social Psychology, 69(4), 719-727. doi: 10.1037/0022-3514.69.4.719

Ryff, C. D., \& Singer, B. H. (1998). The contours of positive human health. Psychological Inquiry, 9(1), 1-28. doi: $10.1159 / 000289026$ 
Ryff, C. D., \& Singer, B. H. (2006). Best news yet on the six-factor model of well-being. Social Science Research, 35(4), 1103-1119. doi: 10.1016/j.ssresearch.2006.01.002

Schimmack, U., Oishi, S., Furr, R. M., \& Funder, D. C. (2004). Personality and life satisfaction: A facet-level analysis. Personality and Social Psychology Bulletin, 30(8), 1062-1075. doi: $10.1177 / 0146167204264292$

Schmutte, P. S., \& Ryff, C. D. (1997). Personality and well-being: Reexamining methods and meanings. Journal of Personality and Social Psychology, 73(3), 549-559. doi: 10.1037/0022-3514.73.3.549

Siegler, I. C., \& Brummett, B. H. (2000). Associations among NEO personality assessments and well-being at midlife: Facet-level analyses. Psychology and Aging, 15(4), 710-714. doi: 10.1037/08827974.15.4.710

Soto, C. J. (2014). Is happiness good for your personality? Concurrent and prospective relations of the Big Five with subjective well-being. Journal of Personality. doi: 10.1111/jopy.12081

Steel, P., Schmidt, J., \& Shultz, J. (2008). Refining the relationship between personality and subjective wellbeing. Psychological Bulletin, 134(1), 138-161. doi: 10.1037/0033-2909.134.1.138

Watson, D., Clark, L. A., \& Tellegen, A. (1988). Development and validation of brief measures of positive and negative affect: the PANAS scales. Journal of Personality and Social Psychology, 54(6), 10631070. doi: 10.1037/0022-3514.54.6.1063

Weiss, A., Bates, T. C., \& Luciano, M. (2008). Happiness is a personal(ity) thing: The genetics of personality and well-being in a representative sample. Psychological Science, 19(3), 205-210. doi:

$10.1111 /$ j.1467-9280.2008.02068.x 